CENTRO DE CIÊNCIAS SOCIAIS

DEPARTAMENTO DE SERVIÇO SOCIAL

PÓS-GRADUAÇÃO LATU SENSU

ESPECIALIZAÇÃO EM ASSISTÊNCIA SOCIAL E DIREITOS HUMANOS

CAPITALISMO CONTEMPORÂNEO: REFLETINDO SOBRE O ESTADO PENAL E A CRIMINALIZAÇÃO DA POBREZA

Por:

Andrea Oliveira Da Silva

Orientador: Prof. Dr. Marcelo Luciano Vieira 


\section{Andrea Oliveira Da Silva}

Capitalismo Contemporâneo: refletindo sobre o estado penal e a criminalização da pobreza

Artigo Científico apresentado ao Programa de PósGraduação em Assistência Social e Direitos Humanos da PUC-Rio como requisito parcial para obtenção do título de Especialista em Assistência Social e Direitos Humanos

Orientador: Prof. Dr. Marcelo Luciano Vieira

Coordenação Central de Extensão

Curso de Especialização em Assistência Social e Direitos Humanos

Rio De Janeiro Fevereiro de 2017

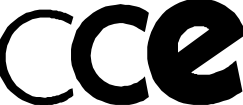

COORDENAÇÃO

CENTRAL DE

E XTENSÃO 


\title{
Capitalismo Contemporâneo: refletindo sobre o estado penal e a criminalização da pobreza
}

\author{
Andrea Oliveira da Silva ${ }^{1}$
}

\section{RESUMO}

O artigo em análise tem o desígnio de refletir sobre o processo de criminalização dos pobres e da pobreza desencadeado pelo capitalismo contemporâneo e sobre a ascensão do estado penal em detrimento do estado social. Pretende-se discutir a forma como o capitalismo pós-industrial opera junto aos segmentos pobres, "disfuncional" ao capital e concluir que o estado penal e a criminalização da pobreza surgiram nos países que empreenderam no caminho neoliberal porque este prometia resolver os dilemas que a mercadorização criava para a manutenção da ordem social e política.

Palavras-chave: estado penal; criminalização da pobreza; direitos humanos; capitalismo.

\section{ABSTRACT}

The article under analysis is designed to reflect on the process of criminalization of the poor and the poverty triggered by contemporary capitalism and on the rise of the criminal state to the detriment of the social state. The aim is to discuss how post-industrial capitalism works alongside the poor segments, "dysfunctional" to capital and to conclude that the criminal state and the criminalization of poverty have arisen in the countries that embarked on the neoliberal path because it promised to solve the dilemmas that Created for the maintenance of social and political order.

Keywords: criminal status; criminalization of poverty; human rights; capitalism.

\footnotetext{
1 Graduada em Serviço Social e Direito pela PUC-Rio. Especialista em Gestão e Recursos Humanos pelo IAG/PUC-Rio. Coordenadora da Rede de Empreendimentos Sociais da PUC-Rio. E-mail: andy3536@hotmail.com
} 


\section{Introdução}

As sociedades capitalistas estão profundamente marcadas pela crise no capitalismo contemporâneo ${ }^{2}$ e pelas estratégias para a retomada das taxas de lucro. Quer seja pelo desemprego e avanço das condições precárias de trabalho, quer seja pela escalada da violência e da criminalização dos indivíduos que não são funcionais ao capitalismo, esta crise e as formas assumidas pelo capital para enfrentar movimentos de resistência afetam a vida da classe trabalhadora.

Ao longo do século XX a pobreza passou de pontual e circunscrita a alguns países para um fenômeno global. Entretanto, a criminalização dos pobres não é uma estratégia nova. A criminalização da pobreza há muito vem sendo temática negligenciada pela sociedade. No passado, o poor law, por exemplo, sistema de ajuda social aos pobres instituído na Inglaterra e Gales, também, conhecido como Lei dos Pobres ou Elisabetana, que definia como pobre todas as pessoas que passavam necessidades, incluindo os indigentes, os velhos, os enfermos e os órfãos e que subsistiu até ao surgimento do Estado de bem-estar moderno depois da II Guerra Mundial - foi uma legislação que expressou nitidamente as formas de controle dos pobres.

Historicamente, no Brasil, se percebe que os pobres nunca tiveram lugar de prestígio na sociedade, ora nobre, ora burguesia. Assim sendo, as pessoas têm se acostumado, no decorrer de várias décadas, a vislumbrar a pobreza como um mal obstinado a dificultar a ascensão do país ao patamar das nações desenvolvidas. Nesse ínterim, sua erradicação tornou-se objetivo precípuo a ser alcançado, não importando o modo em que se dê o processo.

A exacerbada preocupação com o freio à criminalidade, pouco trás questionamentos sobre quais as verdadeiras causas e os principais agentes à frente da propulsão dessa problemática. Assim sendo, torna-se controversa a maneira de enfrentar a situação.

\footnotetext{
${ }^{2}$ Trata-se do conjunto de eventos sociais que se colocam a partir da segunda metade da década de 1970, atingindo seu ápice durante os anos 1980 e 1990. Tais eventos são denominados e conhecidos como reestruturação produtiva e globalização do capital, implicando, já no descortinar do século XXI na emergência do "Estado penal", como forma assumida pelo Estado para dar
} 
$\mathrm{Na}$ lógica da criminalização, os jovens pobres, negros e a população de rua são alvos preferenciais. Desde a Segunda Guerra Mundial, com a experiência do genocídio praticado pelo nacional-socialismo, que a promoção dos Direitos Humanos tem sido proclamada como meta obrigatória pela comunidade das nações. No entanto, sabemos que persistentes violações dos direitos civis, políticos e sociais são tristes realidades em diversas regiões do mundo, sobretudo nos países periféricos nos quais atingem altos níveis de indecência.

Michel Foucault (2002) nos faz concluir que a evolução dos mecanismos de controle social está intimamente ligada com a evolução do capitalismo. Por esta razão, com o fim do estado social a partir dos anos de 1970 e a consequente emergência do estado neoliberal, os mecanismos de controle passaram a tomar novos rumos e a população marginalizada, sem mais contar de proteção do Estado e não tendo mais perspectiva de inclusão no sistema capitalista, passou a ser controlada pelo sistema penal, num processo crescente de criminalização da pobreza.

O método utilizado para a elaboração do presente artigo é um estudo descritivo e doutrinário não tendo, as considerações acima, a intenção de analisar em profundidade a situação no Brasil e, tampouco, no mundo contemporâneo, mas tão somente o objetivo de uma breve contextualização.

\section{Criminalização da pobreza e Direitos Humanos no capitalismo pós- industrial}

Dentre as mudanças mundiais advindas do capitalismo pós-industrial podemos destacar a dispensa do Estado de bem estar e a fragmentação das relações de trabalho. Esse contexto da economia mundial se caracteriza pela grande concentração e transnacionalização do capital, pelo jogo do mercado financeiro, pelo desenvolvimento desigual, pela produção do desemprego e pela proletarização de trabalhadores.

conta, nos países do capitalismo periférico, da gestão da desigualdade social aprofundada e da pretendida desmobilização dos movimentos sociais e das lutas operárias. 
Este modelo de economia mundial foi submetida às exigências do capital financeiro. Todavia, sabemos por Marx que o dinheiro tem um conteúdo eminentemente de desigualdade e de exploração, por esse motivo que, na luta entre o capital e o trabalho, sempre se privilegiou o primeiro em detrimento do segundo colocando os homens contemporâneos, principalmente dos países periféricos, fora do alcance dos ganhos de produtividade do trabalho, ou seja, os excluímos.

Esta população "disfuncional" ao capital, por sua vez, construiu formas de resistência individuais e coletivas para sobreviver ao ataque das forças instituídas. Neste cenário, o Estado lançou mão do aparato policial e do Judiciário no sentido de conter essa "classe perigosa".

A economia globalizada e liberal instaurou assim um processo de exclusão banindo totalmente indivíduos e grupos do processo econômico. Criou-se desta forma uma pobreza estrutural globalizada na qual os pobres não foram incluídos muito menos colocados à margem, eles foram excluídos.

Esta ordem mundial permitiu que sobresse um enorme contingente de trabalhadores sem trabalho, fazendo, assim, crescer a competitividade desleal. Esse movimento marcou e marca a exacerbação do individualismo, quer na vida econômica, quer na ordem política, quer na ordem dos territórios, quer na relação social e afetiva. Conclui-se assim que, a desigualdade advinda da atual ordem mundial é a verdadeira essência do capitalismo.

Esta desigualdade, consequentemente, "impõe" o medo, que por sua vez sempre foi utilizado como pretexto para justificar, legitimar e propagar violações dos Direitos Humanos em diversos lugares e civilizações. No Brasil, por exemplo, os primeiros alvos de "adestramentos", trabalho escravo, punições violentas, desumanas e cruéis foram os índios que, após serem exterminados foram substituídos pelos negros africanos.

Num sistema capitalista onde a riqueza sempre esteve materializada na propriedade privada dos meios de produção, na mercadoria e no dinheiro, é extremamente importante garantir a segurança desta, para evitar que os que não se 
enquadram às novas formas de sobrevivência ou até mesmo não concordam com elas cometam atos considerados ilícitos. Tais indivíduos são os desempregados, mendigos, ociosos etc. e são marginalizados, mas na verdade representam as falhas do próprio sistema. Uma forma de "oficializar" estes inimigos da sociedade moderna é denominá-los "vadios", "vagabundos", "pivetes" dentre outros nomes que estigmatizam os que precisam ser encarcerados e exterminados já que ameaçam à ordem, o progresso do país e os cidadãos de bem.

Os Estados Unidos, segundo Wacquant (2007, p.56) iniciaram a campanha de penalização da pobreza conhecida como a "teoria" das "janelas quebradas" (broken Windows) que sustentava enfaticamente a necessidade de punir os pequenos delitos para prevenir delitos mais graves.

Essa teoria serviu de base criminológica para a reorganização da atividade policial, que foi conhecida como "tolerância zero" ${ }^{3}$. Essa política traduziu-se em uma elevação massiva do orçamento policial, com aumento do número de efetivos e equipamentos policiais, e em maiores poderes e liberdades ao agir policial.

Essa concepção foi exportada como uma exitosa política de luta contra a "insegurança” sendo amplamente assumida pelos governos neoliberais da Europa e da América Latina. Integrando essa propaganda ideológica, os conservadores atribuíram às medidas implementadas o fato de ter reduzido a criminalidade: "A ideia de 'tolerância zero' passou a ser a panaceia, o remédio universal para todos os males da delinquência, das transgressões sociais e da desordem urbana" (DORNELLES, 2008, p. 64).

Segundo o mesmo autor, com essa teoria, o que mudou radicalmente não foi à criminalidade - cujos indicadores mostravam que tendia a manter-se ou a diminuir $^{4}$ - mas a atitude dos poderes públicos com relação aos pobres, considerados o centro irradiador do crime.

\footnotetext{
${ }^{3}$ Implementada a partir de 1993, sob o comando de William Wratton, chefe da polícia de Nova Iorque na gestão do prefeito Rudolph Giuliani.

4 "A quantidade de assassinatos havia caído pela metade entre1990 e 1994, como também os crimes contra o patrimônio caíram 25\% no mesmo período [...]" (WACQUANT, 2002 apud DORNELLES, 2008, p. 63).
} 
Young (2002) colocou o extraordinário paralelo que sempre existiu entre a guerra e a criminalidade, quanto à mobilização da agressividade. Ele destacou que, para criar um "bom inimigo", precisamos ser capazes de nos convencer que eles são as causas de todos os nossos problemas, facultando dirigir a animosidade contra eles. Nós devemos acreditar que eles também seriam, intrinsecamente, diferentes de nós, sintetizando a corrupção, o mal, e a degradação, o que habilitaria e legitimaria ao Estado o uso da violência.

Conforme Zaffaroni (2007, p.18), o conceito de inimigo introduz a dinâmica da guerra no Estado de direito:

\begin{abstract}
"A essência do tratamento diferenciado que se atribui ao inimigo consiste em que o direito lhe nega sua condição de pessoa. Ele é considerado sob o aspecto de ente daninho ou perigoso [...] estabelece-se a distinção entre cidadãos (pessoas) e inimigos (não pessoas), faz-se referência a certos seres humanos que são privados de certos direitos individuais".
\end{abstract}

Neste diapasão, na lógica da guerra, suprimem-se os direitos constitucionais da cidadania e o inimigo é simplesmente um alvo que se deverá destruir. Essa lógica belicista foi introduzida nas políticas de "segurança" pública, implementadas pelos governos neoconservadores; nas quais prevalece a lógica do confronto e a repressão direta. A esse respeito, DORNELLES coloca (2008, p. 181): "Uma lógica que identifica mecanicamente as classes subalternas como agente do crime, como classes perigosas e os bairros e favelas como 'áreas de risco' [...] levando a aplicação de políticas que [...] atingem o conjunto da população mais pobre".

Segundo POTYARA (2014, p.461) as implicações das mudanças regressivas das políticas públicas para os direitos humanos têm sido desastrosas e bem conhecidas por aqueles que conseguem enxergar para além da aparência. Todavia, vale listar os principais óbices que essas mudanças vêm impondo a esses direitos nas suas três dimensões: civil, política e social.

Começando pelos direitos sociais, que apenas $1 / 3$ dos habitantes do planeta foi, e está sendo, contemplado pelos benefícios da globalização ou pela oferta de bens, serviços, conhecimentos e informações que ela propicia via mercado - mas sem que esse 1/3 esteja livre da possibilidade de marginalização. 
Isto porque a busca obsessiva de eficiência e lucratividade neoliberal, por meio de feroz competitividade, só faz aumentar os números dos descartáveis.

Diante dessa tendência, a política social deixou de ser universal para se tornar focalizada na indigência tendo o desmonte dos direitos sociais como consequência a quebra do protagonismo do Estado na provisão e na garantia da política social, ficando essa provisão por conta do mercado e das organizações da sociedade civil, que não têm poderes para garantir direitos.

Essa repulsa por políticas sociais legítimas ajusta-se ao ideal de aumento da repressão ao crime. Há mais de duas décadas vivemos sob a égide de uma Constituição democrática, no entanto, as relações entre os governos e a sociedade caracterizam-se cada vez mais pela ilegalidade e arbitrariedade. Isso fica particularmente claro quando observamos a Justiça Penal onde a atuação do sistema penal demonstra, desde logo, o descaso das autoridades com as garantias formais fixadas na Constituição e nos demais códigos que formam o ordenamento jurídico nacional.

Nesse contexto, as classes mais abastardas economicamente, se isolam em sistemas de segurança privada, contribuindo assim para o predomínio do abismo social em que o Estado não é mais incumbido de implementar políticas redistributivas e instituir princípios de justiça social.

Ivete Manetzeder Keil ${ }^{5}$, no artigo Paradoxo dos Direitos Humanos no Capitalismo Contemporâneo, nos diz que em o Colapso da Modernização Robert Kurz $^{6}$ chama atenção sobre o fato de que hoje o sofrimento do Terceiro Mundo não mais deriva da exploração capitalista da força de trabalho, mas da ausência desta exploração:

\footnotetext{
${ }^{5}$ Antropóloga. Mestre em Antropologia Social pela Universidade Federal do Rio Grande do Sul (1987). Doutora em Antropologia - Sorbonne Paris V Rene Descartes (1995) e Pós-doutorado na École des Hautes Études en Sciences Sociales - EHESS (2001 e também em 2003). Pesquisa poder e subjetividade. Professora PPGEduc Básica - Unisinos.

${ }^{6}$ Filósofo, sociólogo e ensaísta alemão. Robert Kurz defende o fim do emprego. Diz que "não restará ao homem senão inverter o resultado do capitalismo e libertar-se do trabalho" e que a emancipação social não poderá fundamentar-se em tal conceito. Tem uma visão considerada por muitos de pessimista e até mesmo de catastrofista, apesar de sua argumentação lógica encontrar grande repercussão na Europa.
} 
"ninguém precisa da grande maioria dessas massas desarraigadas, levando esta parte uma vida miserável e improdutiva fora de qualquer estrutura de reprodução coerente (...) a maioria da população mundial consiste hoje em sujeitos-dinheiro sem dinheiro, em pessoas que não se encaixam em nenhuma forma de organização social, nem na pré-capitalista, nem na capitalista, e muito menos na pós-capitalista, sendo forçadas a viver num leprosário social que já compreende a maior parte do planeta".

Keil também lembra que para Robert Kurz o conceito ocidental dos direitos humanos, contém como pré-requisito tácito saber se os indivíduos tem valor de venda e poder de compra, pois quem não preenche esses critérios na verdade não é mais um ser humano, mas uma porção de biomassa.

Nessa perspectiva os direitos humanos desempenham na sociedade contemporânea a função de polícia mundial favorecendo os interesses da economia ignorando as violações cometidas pela esfera econômica, pois na medida em que geram reivindicações substanciais, certos direitos materiais não podem ser democratizados como, por exemplo, ricos e pobres participam de eleições em igualdade de condições, mas não podem participar em igualdade de condições de um alto consumo de recursos naturais, ou seja, as regras formais do jogo não se encaixam com as contingências do jogo.

Fazendo uma analogia a "Ensaio sobre a cegueira" de José Saramago, no tocante ao sistema penal brasileiro, encontramos um Estado, que na figura de garantidor dos seus cidadãos, atua de forma controvertida, agindo com base em estigmas e renegando ao caos àqueles que dependem da sua atuação. No livro, os cegos atacados pela epidemia desconhecida são excluídos, tanto pelo Estado, quanto pela sociedade, sendo então submetidos a viverem em um sanatório. Todavia, com o tempo, a capacidade de lotação do espaço é excedida e os ali presentes se veem em situações subumanas de sobrevivência.

A alusão, portanto, segue a condição dos presos no sistema carcerário brasileiro que, tais quais os cegos tratados no ensaio de Saramago, têm seus direitos fundamentais inobservados, sobretudo, pelo Estado. Um sistema estéril, no qual sua aparente "função" ressocializadora se demonstra ineficaz; apresentando-se, ao revés, ainda mais denegridora da essência humana destas pessoas em verdadeira afronta ao princípio estrutural do Estado Democrático de 
Direito, no que tange à Dignidade da Pessoa Humana, albergado pelo art. $1^{\circ}$, III, da Constituição Federal de 1988.

Art. $1^{\circ}$ - A República Federativa do Brasil, formada pela união indissociável dos Estados e Municípios e do Distrito Federal, constitui-se em Estado Democrático de Direito e tem como fundamentos: III - a dignidade da pessoa humana;

Foucault aponta, em Vigiar e Punir (2002), a existência de uma diferenciação dos objetivos ideológicos e dos objetivos reais do sistema carcerário: os objetivos ideológicos da prisão seriam a repressão e redução da criminalidade, enquanto os objetivos reais da prisão seriam a repressão seletiva da criminalidade e a organização da delinquência, definida como tática política de submissão.

No Brasil as escolhas político-criminais, garantistas materializam o espirito contido na Constituição Federal de 1988 que emerge o sistema de proteção social fundada na noção de direito, ao mesmo tempo em que se anuncia o neoliberalismo e sua receita desregulamentadora de direitos e o Estado mínimo para as políticas sociais, corrobora para a construção de uma cultura de respeito aos próprios direitos humanos.

Sob essa perspectiva, no Brasil, os direitos humanos exercem duas finalidades precípuas. Na primeira eles são considerados como standards de proteção da pessoa humana. A outra função que exercem diz respeito à própria orientação do sistema punitivo, pois se tornam o fundamento racional que legitima o próprio sistema político-criminal a partir da estrita observância da dignidade da pessoa humana ${ }^{7}$.

Assim sendo, ordens governamentais ao invés de buscarem os motivos encaminhadores a determinado mal, procurando, conseguintemente, uma forma de erradicá-lo, opta pela medida mais prática: a segregação. Assim, apresenta-se um sistema prisional brasileiro político e ideologicamente seletivo, no qual se prefere

\footnotetext{
${ }^{7}$ Art. $1^{\circ}$, inc. III da CF/88. Princípio da Dignidade da Pessoa Humana instituído como valor supremo, definindo-o como fundamento da República. O que significa dizer que, no âmbito da ponderação de bens ou valores, este princípio justifica a restrição de outros bens constitucionalmente protegidos, ainda que representados em normas que contenham direitos fundamentais, de modo a servir como verdadeiro e seguro critério para solução de conflitos.
} 
tratar a criminalidade em suas vias transversas, focando no fim, mas não buscando os meios.

Neste fim, temos que o nosso atual sistema punitivo se enraíza em uma visão estática de direitos humanos, por consequência, produzindo uma resposta totalmente ineficaz e apolitizada; quando, para a resolução do problema, esses direitos deveriam se entendidos enquanto processo de luta; unindo os controlados pelo sistema em um combate pelo reconhecimento de conquista das suas necessidades reais.

Embora os direitos humanos tenham contribuído para o aumento da participação de indivíduos e grupos na produção da cidadania e possam ser considerados essencialmente como uma conquista das lutas populares e movimentos sociais a experiência cotidiana mostra que neste domínio surgem hoje novos obstáculos e desafios que se somam aos já existentes na época e que ainda não foram superados.

\section{Estado penal e pobreza}

No sistema penal $^{8}$, pautado pelos direitos humanos, a privação da liberdade é o ultimo recurso a ser adotado como forma punitiva do indivíduo. No entanto, sua história e a evolução da pena privativa de liberdade seguem a lógica do sistema capitalista, de forma que sua consolidação definitiva, entendendo-a como a maneira mais eficiente e menos danosa de tratar o fenômeno delitivo, decorre também da concretização do capitalismo.

Foucault (2002) nos faz entender que as penas, imersas no sistema político do direito, possuem relação premente com a economia e, por consequência, com os bens jurídicos defendidos pelo Estado (Liberal).

\footnotetext{
8 "Por 'sistema penal' entendemos [...] a soma dos exercícios de poder de todas as agências (policial, judiciária e penitenciária)" (ZAFFARONI, 2001, p. 144).
} 
Sendo assim, na linha de raciocínio das casas de trabalho, "o sistema punitivo seria um subsistema social garantidor do sistema de produção da vida material, cujas práticas punitivas consubstanciam uma economia política do corpo para criar docilidade e extrair utilidade das forças corporais”. (CIRINO, 2005).

Comprovadamente, num sistema punitivo as evidências do Estado penal se exprimem de, pelo menos, duas maneiras, no estigma e na criminalização.

O estigma é que pobres e negros aparecem na mídia como autores de atos criminosos que, apanhados de maneira imediatista e preconceituosa, são associados, em seu conjunto, às práticas de crimes. Isto é produzido e/ou apropriado pelos segmentos dominantes, na prática e ideologicamente, no sentido de obter a licença de "caçá-los e prendê-los". Assim, eles aparecem como perigosos para a população em geral. De toda forma, cria-se a "licença geral" para criminalizar todos os jovens pobres e negros.

Destarte, o estigma é de que, por sua condição social e étnica, estão predispostos a se tornarem ameaçadores. Para o público, aparecem como ameaças e para a reprodução do capital poderão ser utilizados para desfocar o debate e discussões sobre o direito, sobre a cidadania, sobre a proteção social.

O Estado penal, além de criminalizar pobres e negros, dissemina o "medo ao outro", ou seja, os efeitos nocivos da crise avançam sobre as relações sociais, produzindo desconfiança, discriminação e ratificando as desigualdades. O tratamento dispensado a população moradora de rua, invisível aos olhos da sociedade e das políticas sociais, por exemplo, é invariavelmente no sentido de expulsá-la dos grandes centros em uma tentativa clara de "limpeza" do espaço urbano e desresponsabilização estatal.

Vários estudos, como os de Wacquant, indicam a prevalência contemporânea de um "Estado penal" que, rejeitando a ética da proteção social, criminaliza e pune os pobres, os diferentes, os desiguais, os estranhos, que não conseguiram se colocar acima ou à parte do vasto sistema de insegurança social capitalista. Nesse sistema, pontua o autor, referindo-se à América do Norte, só escapa "a alta nobreza das empresas e do Estado" (2007, p. 24), o que revela o paroxismo a que 
chegou a divisão de classes numa época em que muitos acreditam não mais existir classes sociais.

Efetivamente, sob a égide do Estado penal, as políticas de enfrentamento à pobreza e à desigualdade social tornaram-se antissociais. E, como tal, desincumbiram-se de quaisquer responsabilidades que possam caracterizar deveres do Estado e direitos dos cidadãos. Pautadas por uma ortodoxia moralista burguesa, que contrapõe o mérito ao direito e a autorresponsabilização individual à proteção social pública, tais políticas têm apenado a quem mais delas precisam — cidadãos que vivem do seu trabalho - e privilegiado os interesses do capital.

Wacquant (2007, p.32) nos explica ainda como o excessivo custo econômico do aprisionamento de massa serviu de base de argumentação para que o governo norte americano recorresse ao setor privado que é orientado pela ideologia da mercantilização. Nesta conjuntura, empresas privadas entraram no mercado da construção e gestão de prisões, embora elas não tivessem sido as únicas. Também "lucraram" setores envolvidos em garantir determinados bens e serviços, tais como alimentação, telefonia, transporte, tecnologias de identificação e vigilância, atenção médica, entre outros.

Como uma novidade nas formas de penalização da pobreza característica do capitalismo contemporâneo, os "indesejáveis", além de serem vítimas do desemprego em massa, do trabalho precário, do recuo das políticas sociais e do aumento de medidas mais punitivas, foram submetidos à lógica perversa do encarceramento privado, para desta maneira contribuírem com a acumulação de capital. Portanto, sob a justificativa de pôr freio à criminalidade, incita-se a construção de prisões de segurança máxima, mas o que não se revela é a sua função oculta.

De outro lado, assiste-se à recorrente implementação de políticas habitacionais de "confinamento", pelas quais os segmentos pobres são transferidos para conjuntos habitacionais populares, sem infraestrutura adequada para sua sobrevivência sendo, na maioria das vezes, deixados à própria sorte. Assim, sobrepondo-se à pretendida qualidade de vida do habitat, prevalecem à 
quantidade e a economia de escala no processo construtivo de unidades habitacionais em espaços compactos, além da configuração de territórios inóspitos de vida e moradia para pobres.

Da condição de pobre, subalterno à possibilidade de pretenso ator e cidadão, idealizado e reverenciado na retórica dos discursos e nas diretrizes das atuais políticas sociais, a propalada cidadania acaba reduzida a iniciativas neoliberais de inclusão do pobre à condição de mero agente consumidor e cliente, cidadão sem vez e sem voz no território das políticas e das práticas do consenso.

Nesses espaços produzidos, denominados condomínios populares fechados, localizados principalmente em bairros pobres já estabelecidos na periferia das grandes cidades, que nos permite reconhecer o embrionário surgimento de "bolhas urbanas", figurativamente assim designado haja vista a reconhecida forma urbana de confinamento de pobres que promete implodir em suas contradições historicamente acumuladas.

Nestes termos, nos atuais e emblemáticos espaços de disputas - cenários da "guerra de poder", as formas de representações construídas na perspectiva de enfrentamento ao projeto neoliberal são em muitos casos contraditórias, além de revelar a "confluência perversa de projetos políticos antagônicos em disputa" (DAGNINO, 2002, p. 2).

Segundo Loïc Wacquant (2007), que estudou a segregação racial, a pobreza, a violência urbana, a desproteção social e a criminalização na França e nos Estados Unidos da América no contexto do neoliberalismo, os moradores desses espaços são penalizados e, em geral, culpabilizados e desqualificados, tendo seus "fracassos" associados à pobreza e aos pertencimentos étnicos.

Em relação à questão abordada pelo autor, vê-se que no Brasil se presencia essa mesma lógica de culpabilização desqualificação dos pobres e negros, ainda que recoberta pelo discurso da "preguiça", "da falta de vontade" ou "incapacidade para o trabalho". 
Em razão da formação sócio histórica da nossa sociedade, os pobres e a pobreza se constituíram presenças marcantes, sobretudo por conta do escravismo e da forma pela qual o capitalismo se desenvolveu no país. Sem contar que, no Brasil, a pobreza era vista como sinônimo de "vadiagem" ou qualquer outro elemento vinculado à delinquência e à criminalidade, ou seja, em grande parte da história do país, a questão social foi tratada como questão de polícia.

Pela análise de Wacquant (2007) fica evidente que a emergência do chamado Estado penal em detrimento do Estado social, encontra-se no contexto da crise do capital, a qual afeta todas as instâncias da vida social, sendo que a ascensão do Estado penal não constitui um fenômeno apenas no Brasil.

Estudando a retratação da rede de segurança social que ocorreu nos EUA e em toda a Europa a partir dos anos de 1990, Wacquant (2007) concluiu que penalização da pobreza emergiu como um elemento central da implementação doméstica e da difusão através das fronteiras do projeto neoliberal, do "punho de ferro" do Estado penal, unido à “mão invisível” do mercado, ambas em conjunção com o esgarçamento da rede de seguridade social.

Para ele o Estado penal foi implantado nos países que empreenderam a rota neoliberal porque prometia resolver dois dilemas que a mercadorização cria para a manutenção da ordem social e política. A primeira delas seria a restrição aos deslocamentos crescentes causados pela normalização da insegurança social na base da estrutura de classe e da estrutura urbana e a segunda a restauração da autoridade da elite governante, ao reafirmar "a lei e a ordem" apenas quando essa autoridade está sendo solapada pelos fluxos acelerados de dinheiro, capital, comunicações e pessoas através das fronteiras nacionais, bem como pela compressão da ação estatal por órgãos supranacionais e pelo capital financeiro.

Atualmente, os mecanismos disciplinares precisam gerir também a sempre crescente massa de desempregados e excluídos da sociedade capitalista. Se o sistema penal da industrialização impunha a disciplina do trabalho, o sistema penal do neoliberalismo tem que impor a disciplina do desemprego (MORAIS, 2006, p.38). 
Entende-se que, nessa avançada fase do capitalismo, a violência não é uma ameaça ao sistema, mas, sim, um aspecto intrínseco a ele, tanto quanto o incentivo exacerbado ao consumo, à livre iniciativa, à exploração do trabalhador. Isso porque ela é, tão somente, consequência da desigualdade e da opressão, também componentes inegáveis do sistema. Entretanto, o entendimento hegemônico não faz essa correlação de causa e efeito, o que acaba por reduzir a violência como um mal social com fim em si mesmo. Quando, por exemplo, há o "arrastão" em bairro nobre de alguma capital do país (expressão coloquial utilizada, sobretudo, pela mídia), a compreensão majoritária é no sentido de culpar apenas os transgressores da lei, sem questionar que essa ação é resultado de uma soma de omissões estatais em suas vidas. Não se culpa o Estado, porque culpá-lo significaria problematizar a opção político-econômica por um modelo estatal capitalista, o que culminaria no clamor do povo por uma mudança estrutural e não meramente individual e repressiva.

Desse modo, observamos que, na sociedade moderna, a distribuição desigual das necessidades reais dos indivíduos decorre de uma violação aos seus direitos humanos. Realidade essa, por sua vez, imersa em um contexto ainda mais vasto no que tange à violência estrutural e institucional cometida pelo Estado.

Assim, em relação ao sistema penitenciário brasileiro, conclui-se que a preocupação do sistema punitivo não é o de resolver as maiores problemáticas da sociedade, a exemplo dessa violência estrutural. O código penal, tal qual todo o sistema, evita enfrentar os problemas estruturais, fazendo a sociedade acreditar que essa violência inexiste, representando, para tanto, apenas a de caráter individual - aquela praticada por um indivíduo - que, a seu turno, constitui uma parcela ínfima da problemática em análise.

Portanto, é fácil compreender a lógica do sistema punitivo no Brasil, o qual tem selecionado a classe marginalizada do seu corpo social a fim de solapar a pobreza. “A 'guerra contra pobreza', assumida como bandeira de luta e plataforma de atuação pelo Estado Democrático de Direito, é substituída por uma 'guerra contra os pobres', tidos como bode expiatório de todos os males do país" (WACQUANT, 2007). 


\section{Considerações Finais}

Ao longo da história pode-se verificar que os seres humanos sempre foram tratados de modo diferenciado. A divergência no tratamento sempre foi baseada na condição dessas pessoas. Alguns seres humanos eram considerados indesejáveis, sendo vistos como inimigos da sociedade por serem "perigosos".

A particularidade da formação sócia histórica brasileira aprofunda a criminalização das consideradas "classes perigosas" tendo-se como consequência do processo o extermínio de jovens e da população de rua com claro viés étnicoracial e a "guetização" dos pobres.

Atualmente, em seu discurso, o Estado sacraliza o mercado e diz zelar pela liberdade, mas, na verdade, reserva o liberalismo e seus benefícios àqueles que estão no topo, enquanto impõe o paternalismo punitivo àqueles que estão na base da pirâmide social. Corrobora com a reprodução do capital agindo, "em nome da lei”, com sua força repressora junto aos pobres em nome da segurança da propriedade e dos proprietários. É o Estado penal “colocando ordem" na sociedade tendo como discurso legitimador a máxima repressão, olvidando-se, contudo, do caráter preventivo que a política criminal deve ter.

Somente desconfigurando a violência estrutural, institucionalizada na figura de um Estado corrupto e desapegado as causas sociais, é que se conseguirá descriminalizar a pobreza, nutrindo a luta por uma sociedade menos desigual e excludente.

Do homem primitivo até os momentos atuais, o que acaba por se verificar é que deve existir numa proteção dos direitos mínimos, afinal, a espécie humana possui razão e é dotada de necessidades, dentre elas necessidades mínimas, o que implica em garantir aos cidadãos do mundo uma vida sadia. O Capitalismo possui seu campo de atuação e desenvolvimento, todavia, seu pressuposto deve respeitar os direitos humanos, que foram criados de forma a garantir a preservação da espécie humana, tentando eliminar inclusive resquícios de crueldade. 
Esta conjuntura é fruto da sociedade moderna que tem como característica primária o individualismo e que, nos últimos anos, a chamada sociedade do risco, marcada pelo voluntarismo, pelo sentimento de insegurança e vitimização.

\section{Referências Bibliográficas}

BARATTA, Alessandro. Criminologia Critica e critica do direito penal: introdução à sociologia do direito penal. Trad. Juarez Cirino dos Santos. 3. ed. Rio de Janeiro: Renavan, 2002.

BATISTA, Vera Malaguti. Lö̈c Wacquant e a questão penal no capitalismo neoliberal. Rio de Janeiro: Revan, 2012.

BRISOLA, Elisa. SER Social, Brasília, v. 14, n. 30, p. 127-154, jan./jun. 2012.

CALLEGARI, André (Org.); GÜNTHER, Jakobs; MELIÁ, Manuel. Direito penal do inimigo: noções e críticas. Trad. Nereu José Giacomolli. Porto Alegre: Livraria do Advogado, 2007.

DORNELLES, J. R. Conflito e segurança. Rio de Janeiro: Lumen Juris, 2008.

FOUCAULT, Michel. Vigiar e Punir: história da violência nas prisões. 20. ed. Trad. Raquel Ramalhete. Petrópolis: Vozes, 1977.

FOUCAULT, Michel. Vigiar e punir: nascimento da prisão. 25. ed. Trad. Raquel Ramalhete. Petrópolis: Vozes, 2002.

IAMAMOTO, M. V. A questão social no capitalismo. Revista Temporalis. Brasília: Abepss, n. 3, p. 09-32, jan.-jul./ 2004.

Kilduff, Fernanda. O controle da pobreza operado através do sistema penal. Rev. Katál. Florianópolis v. 13 n. 2 p. 240-249 jul./dez. 2010

NETO, José Paulo e BRAZ, Marcelo. Economia Política: uma introdução crítica. São Paulo: Cortez, 2007. Vol. I (Biblioteca de Serviço Social).

PEREIRA, Potyara Amazoneida P. SIQUEIRA, Marcos César Alves. Política social e Direitos Humanos sob o jugo imperial dos Estados Unidos. Serv. Soc. Soc., São Paulo, n. 119, p. 446-467, jul./set. 2014.

PEREIRA, Potyara. A. P.; STEIN, R. H. Política Social: universalidade versus focalização. Um olhar sob a América Latina. In: BOSCHETTI, I. et. al. Capitalismo em crise, política social e direitos. São Paulo: Cortez, 2010, p. 111-112.

SANTOS, Milton. A urbanização brasileira. 5. ed. São Paulo: Edusp, 2005.

WACQUANT, Loïc. Punir os pobres. 2. ed. Rio de Janeiro: Revan, 2007. 
WACQUANT, Loïc. Três Etapas para uma Antropologia Histórica do Neoliberalismo Realmente Existente. Caderno GRH, Salvador, V. 25, $\mathrm{n}^{\circ}$ 66, p. 505518, Set/Dez. 2012.

YOUNG, J. A sociedade excludente. Rio de Janeiro: Revan, 2002.

ZAFFARONI, R. E. O inimigo no Direito Penal. Rio de Janeiro: Revan, 2007.

\section{Artigos eletrônicos}

BIAR, Renato Prata. Brasil: a criminalização da pobreza. Rede de Comunidades e movimentos contra a violência. Disponível em:

http://www.adital.com.br/site/noticia.asp?lang=PT\&cod=30495. Acesso em: 28/11/2016.

GALVÃO, Giovana Mendonça e MARTINS, Tallita de Carvalho. Criminalização da Pobreza: o produto de uma violência estrutural. Revista Transgressões: ciências criminais em debate. Disponível em: https://periodicos.ufrn.br/transgressoes/article/viewFile/6576/5089. Acesso em 27/11/2016.

KEIL, Ivete Manetzeder. Paradoxo dos Direitos Humanos no Capitalismo Contemporâneo. Disponível em:

http://www.dhnet.org.br/direitos/textos/textos_dh/ivete.htm . Acesso em: $11 / 05 / 2016$. 